\title{
Myths about Insulin Resistance: Tribute to Gerald Reaven
}

\author{
Sun H. Kim ${ }^{1}$, Fahim Abbasi ${ }^{2}$ \\ Divisions of ${ }^{1}$ Endocrinology, Gerontology, and Metabolism, ${ }^{2}$ Cardiovascular Medicine, Stanford Diabetes Research Center, \\ Stanford University School of Medicine, Stanford, CA, USA
}

Gerald Reaven was often called the "father of insulin resistance." On the 1-year anniversary of his death in 2018, we challenge three myths associated with insulin resistance: metformin improves insulin resistance; measurement of waist circumference predicts insulin resistance better than body mass index; and insulin resistance causes weight gain. In this review, we highlight Reaven's relevant research that helped to dispel these myths associated with insulin resistance.

Keywords: Insulin resistance; Metformin; Waist circumference; Weight gain

\section{INTRODUCTION}

Gerald Reaven was an active emeritus professor of Medicine at Stanford University until his death at the age of 89 on February 12, 2018 (Fig. 1). He is widely credited with establishing the importance of insulin resistance in human disease, especially

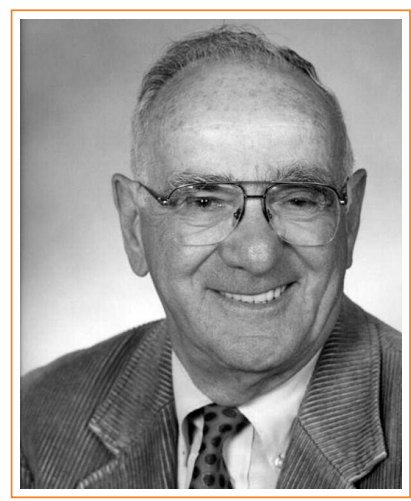

Fig. 1. Gerald Reaven (1928 to 2018). type 2 diabetes mellitus (T2DM) and cardiovascular disease [1]. He was a rigorous physician scientist who often challenged medical dogma. Here we discuss three common medical myths related to insulin resistance and how Reaven's research helped to dispel them.

\section{MYTH: METFORMIN IMPROVES INSULIN RESISTANCE}

Metformin is a widely-prescribed drug [2] and generally recommended as the first-line treatment for T2DM [3]. Metformin is a biguanide (formed via fusion of two guanidine molecules), and its glucose-lowering properties have been appreciated since the 1920s [4]. Less potent than other biguanides, like phenformin and buformin, metformin initially received less clinical attention. When other biguanides were withdrawn from the market due to increased risk of lactic acidosis in the 1970s, metformin was spared but mostly rejected. Although available in Europe since the 1950s, metformin did not receive drug approval in the

\section{Copyright $\odot 2019$ Korean Endocrine Society}

This is an Open Access article distributed under the terms of the Creative Commons Attribution Non-Commercial License (http://creativecommons.org/ licenses/by-nc/4.0/) which permits unrestricted non-commercial use, distribution, and reproduction in any medium, provided the original work is properly cited.
Received: 1 February 2019, Revised: 14 February 2019,

Accepted: 22 February 2019

Corresponding author: Sun H. Kim

Division of Endocrinology, Gerontology and Metabolism, Stanford Diabetes

Research Center, Stanford University School of Medicine, 300 Pasteur Dr,

S-025, Stanford, CA 94305-5103, USA

Tel: +1-650-723-8284, Fax: +1-650-725-7085

E-mail: sunhkim@stanford.edu 
United States (US) until 1994. Reaven is credited as a key individual who engaged with the U.S. Food and Drug Administration to design clinical trials, discuss data and to consider clinical use of metformin in the USA [4].

Jean Sterne is credited for suggesting the name "glucophage" (meaning glucose eater) for metformin [4]. Although the glucose-lowering effects of metformin have been known for some time and validated in large clinical trials such as the UK Prospective Diabetes Study [5], the mechanism of action of metformin continues to be actively debated and investigated. The pervasive view for mechanism of action is that metformin improves insulin sensitivity [6,7]. Here, we should define the term "insulin sensitivity" which is often used to describe peripheral insulin sensitivity or insulin-mediated glucose uptake (IMGU) at the level of the muscle. IMGU can be quantified by the hyperinsulinemic clamp [8] or the insulin suppression test [9]. Natali and Ferrannini [10] reviewed studies using the hyperinsulinemic clamp technique and found no significant effect of metformin treatment on IMGU compared to placebo in individuals with T2DM. Metformin treatment also did not improve IMGU as measured by the insulin suppression test in individuals with prediabetes selected to have impaired glucose tolerance [11].

Treatment with metformin can variably reduce insulin concentrations [12,13], and this finding has led to misconceptions about metformin's mechanism of action. When both glucose and insulin concentrations fall in response to an experimental manipulation, it is often assumed that these parallel changes reflect an improvement in IMGU. If metformin treatment does not improve IMGU, what then is the mechanism of metformin?

Metformin treatment is generally believed to decrease hepatic glucose production $[6,10,14]$; however, Abbasi et al. [15,16] showed no effect of metformin treatment on endogenous glucose production in individuals with T2DM. Instead, Abbasi et al. $[15,16]$ showed that metformin treatment decreases free fatty acid (FFA) concentrations at basal insulin concentrations and increases metabolic clearance rate of glucose. They hypothesized that metformin suppresses lipolysis during fasting and thus enhances glucose clearance at basal insulin concentrations.

In order to appreciate this physiology, it is important to remember that insulin inhibits lipolysis in adipose tissue at lower insulin concentrations than are needed to stimulate glucose uptake in muscle. Using graded insulin-infusion studies, Swislocki et al. [17] demonstrated that FFA concentrations are suppressed at half maximal levels when insulin concentrations are raised from 6 to $20 \mu \mathrm{U} / \mathrm{mL}$. On the other hand, IMGU in muscle is stimulated when insulin concentrations reach $>50 \mu \mathrm{U} / \mathrm{mL}$
Table 1. Insulin Action and Metformin Mechanism Depend on Insulin Concentrations

\begin{tabular}{|c|c|c|}
\hline & $\begin{array}{l}\text { Basal insulin } \\
(<20 \mu \mathrm{IU} / \mathrm{mL})\end{array}$ & $\begin{array}{l}\text { High insulin } \\
(>50 \mu \mathrm{IU} / \mathrm{mL})\end{array}$ \\
\hline Normal physiology & $\begin{array}{l}\text { Regulation of lipolysis } \\
\text { in adipose tissue }\end{array}$ & $\begin{array}{l}\text { Regulation of glucose } \\
\text { uptake in muscle }\end{array}$ \\
\hline $\begin{array}{l}\text { Type } 2 \text { diabetes melli- } \\
\text { tus }\end{array}$ & $\uparrow$ Lipolysis, $\uparrow$ FFA & $\downarrow$ Glucose uptake \\
\hline Metformin treatment & $\begin{array}{l}\downarrow \text { Lipolysis, } \downarrow \text { FFA, } \\
\uparrow \text { metabolic clearance } \\
\text { rate of glucose }\end{array}$ & $\begin{array}{l}\text { No change in glucose } \\
\text { uptake }\end{array}$ \\
\hline
\end{tabular}

$[8,18]$. FFA concentrations are almost maximally suppressed when insulin concentrations are raised to this level [17]. Thus, Swislocki et al. [17] elegantly demonstrated that evaluation of insulin action at the level of the adipose tissue versus muscle needs to be studied at different insulin concentrations.

To evaluate the effect of metformin on lipolysis, Reaven infused a low dose of insulin at $5 \mathrm{mU} / \mathrm{m}^{2} / \mathrm{min}$, as well as somatostatin to inhibit endogenous insulin and glucagon secretion. For comparison, the insulin infusion rates are greater than 20 $\mathrm{mU} / \mathrm{m}^{2} / \mathrm{min}$ during the hyperinsulinemic clamp [8] and insulin suppression test [9] to measure IMGU. Using this low-dose insulin infusion protocol, Abbasi et al. $[15,16]$ found that FFA concentrations are lower and glucose clearance is higher after metformin treatment. They concluded that metformin suppresses lipolysis, leading to lower ambient FFA concentrations, and improves glucose clearance. Thus, metformin improves basal, but not insulin-stimulated glucose disposal. Table 1 shows a summary of proposed mechanisms of action for metformin.

The molecular mechanisms governing effects of metformin on lipolysis and glucose clearance still require clarification. Metformin may inhibit lipolysis $[19,20]$ by stimulating 5' AMPactivated kinase (AMPK) [21]. However, whether this fully accounts for the observed reduction in FFA after metformin treatment remains unclear [22].

\section{MYTH: MEASUREMENT OF WAIST CIRCUMFERENCE PREDICTS INSULIN RESISTANCE BETTER THAN BODY MASS INDEX}

Given the well-established fact that weight gain increases risk for insulin resistance and associated cardiometabolic diseases, many investigators have focused on identifying the ideal mea- 
sure of obesity (e.g., waist circumference [WC] vs. body mass index [BMI]). Reaven had always emphasized that most measures of obesity provide similar associations with insulin resistance. In fact, he argued that the central question should not be how to assess degrees of obesity but "how to best identify the subset of those individuals who are at increased risk of developing many adverse clinical syndromes because of excess adiposity [23]."

The notion that abdominal obesity initiates cardiometabolic abnormalities is widely held [24], and WC is codified as part of the metabolic syndrome criteria [25]. Other criteria for the metabolic syndrome include cutpoints for fasting glucose, triglyceride and HDL-C concentration and blood pressure [26], all of which represent cardiometabolic abnormalities that arise from insulin resistance. In contrast, WC is a measure of adiposity that may increase risk for insulin resistance but it does not result from nor does it assure the presence of insulin resistance.

Most investigators attribute the concept of the metabolic syndrome to Reaven [1] and his description of "syndrome X"-a cluster of metabolic abnormalities (hyperinsulinemia, glucose intolerance, dyslipidemia, and hypertension) associated with insulin resistance. Reaven [27], however, did not believe in the utility of the metabolic syndrome criteria, and felt the inclusion of a measure of adiposity was unnecessary and the choice of WC over BMI arbitrary [28].

Indeed, Farin et al. [29], Abbasi et al. [30], and Sung et al. [31] showed that the relationship between BMI and WC are similarly related in both men and women. BMI and WC are highly correlated with one another with an $r$ value $>0.8$ [29-31]. Moreover, the relationship between BMI and WC are similarly related to quantitative measures of IMGU (peripheral insulin resistance) in both men and women [29]. Fig. 2 shows the relationship between BMI and WC in 751 individuals (440 women, 311 men) and the relationship between BMI and WC with insulin resistance (quantified by steady-state plasma glucose [SSPG], during the insulin suppression test). Again the $r$ value between BMI and WC in both women $(r=0.84)$ and men $(r=0.86)$ are high, and the relationships between both measures of adiposity with insulin resistance are similar.

Given lower BMI thresholds for Asians, there has also been a greater emphasis on identifying abdominal obesity as a surrogate measure for insulin resistance in these populations [26]. Reaven however showed that BMI and WC were similarly related to cardiometabolic risk in South Koreans [31] and South Indians [30,32].

As BMI and WC are crude measures of obesity, many have
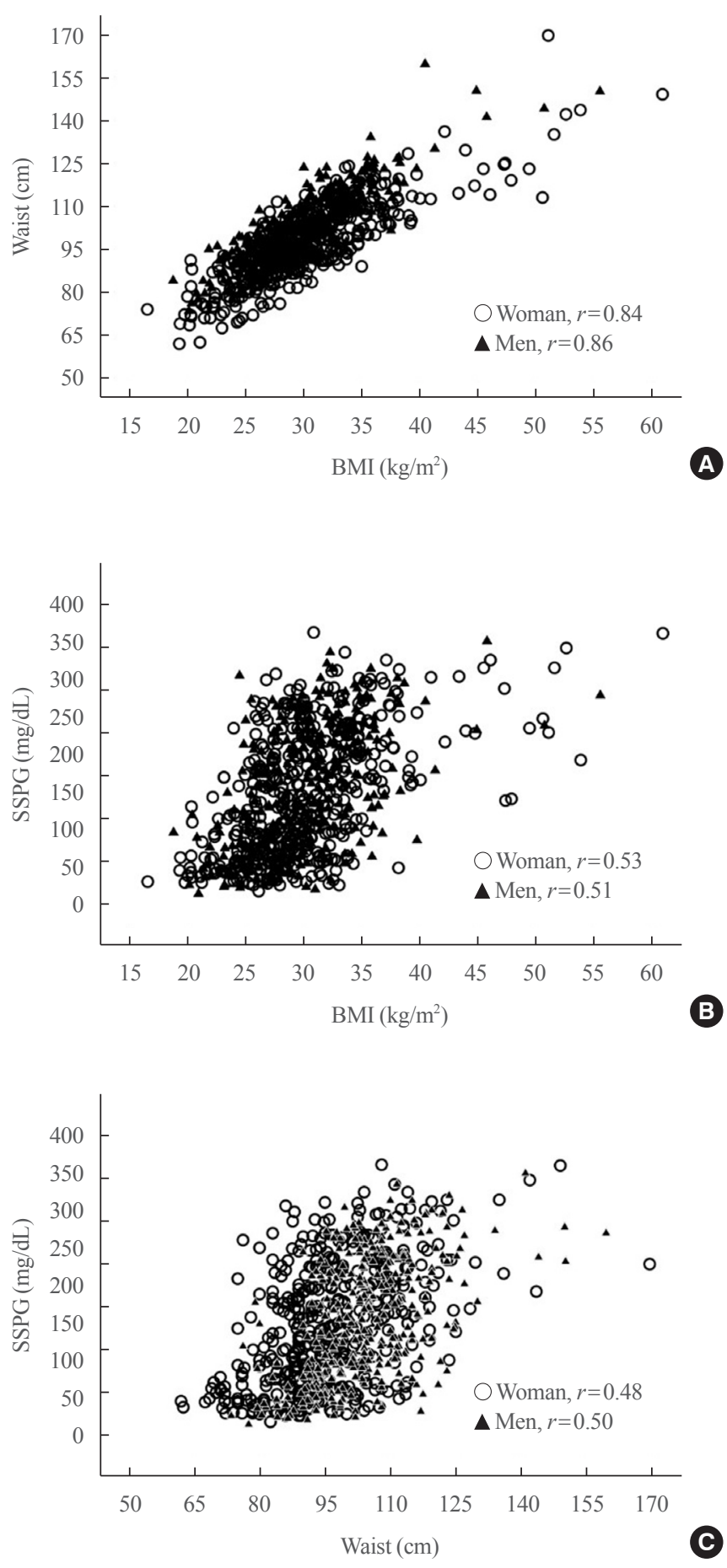

Fig. 2. Relationship among waist circumference, body mass index (BMI), and insulin resistance. (A) BMI and waist circumference are highly correlated with each other in both women (open circle, $n=440$ ) and men (solid triangle, $n=311$ ). Insulin resistance as quantified by measuring the steady-state plasma glucose (SSPG) during the insulin suppression test is positively and similarly associated with both (B) BMI and (C) waist circumference. All Pearson's $r$ values were significant $(P<0.001)$. 
argued that the volume of certain fat depots, especially visceral fat, associate more closely with cardiometabolic risk [33]. However, most measures of fat (visceral, subcutaneous, and total fat) correlate highly with one another and with measures of insulin resistance [28]. Thus, Reaven [28] argued that the "untoward effect of excess adiposity on insulin resistance, associated CVD risk factors and adverse clinical outcomes seems to be quite comparable, whether overall obesity or abdominal obesity is used as the index of adiposity."

\section{MYTH: INSULIN RESISTANCE CAUSES WEIGHT GAIN}

Any measure of obesity is positively associated with insulin resistance, and weight gain likely increases insulin resistance. A popular myth has emerged that argues for the idea that insulin resistance enhances weight gain and/or prevents weight loss. This is the premise for bestselling weight-loss books such as "The obesity code" by Fung [34].

Insulin-resistant individuals compensate for a decrease in insulin action with an increase in plasma insulin concentration [35]. Since insulin stimulates lipogenesis [36], some have contended that the hyperinsulinemic state - which is necessary to compensate for insulin resistance - may hinder weight loss. Zavaroni et al. [37], however, disproved this hypothesis and showed that the degree of insulin response during an oral glucose tolerance test does not predict weight gain over 14 years of follow-up. In this study, adults with a baseline mean age of 40 years were stratified into quartiles based on their 2-hour insulin concentration after a 75-g oral glucose challenge. Insulin concentrations ranged from $18 \mu \mathrm{IU} / \mathrm{mL}$ in the lowest quartile to 106 $\mu \mathrm{IU} / \mathrm{mL}$ in the highest. Although there was nearly a 6-fold difference in insulin concentrations, and presumably similar range of insulin resistance, weight gain was similar among the quartiles over 14 years of follow-up.

McLaughlin et al. [38] also showed that baseline differences in insulin resistance measured by the insulin suppression test did not predict degree of weight loss in response to a hypocaloric diet. In another study, obese women (BMI 30 to $36 \mathrm{~kg} / \mathrm{m}^{2}$ ) who were characterized as either insulin sensitive or insulin resistant based on the insulin suppression test lost the same degree of weight in response to a hypocaloric diet and sibutramine (an older weight-loss medication which has subsequently been discontinued) over a 4-month period [39]. Insulin-resistant women lost $8.6 \mathrm{~kg}$ and insulin-sensitive women $7.9 \mathrm{~kg}$. Insulin-resistant women also significantly improved their degree of insulin resis- tance by $34 \%$, suggesting that IMGU can be modified by weight loss.

Recently, Gardner et al. [40] showed that overweight/obese individuals lost the same amount of weight on low-fat and lowcarbohydrate diets, regardless of their plasma insulin concentrations (measured at 30 minutes during the 75 -g oral glucose tolerance test). When individuals were stratified by tertiles of plasma insulin concentrations, the degree of weight loss did not vary across the tertiles, further supporting the idea that the degree of hyperinsulinemia does not change the ability of individuals to lose weight. Furthermore, the type of diet (low-fat vs. low-carbohydrate) or diet genotype (which suggested greater response to either low-fat or low-carbohydrate diets, or neither) also did not change the ability of individuals to lose weight. In conclusion, overweight/obese insulin-resistant individuals can lose weight to the same degree as insulin-sensitive individuals.

\section{CONCLUSIONS}

This review challenges three common myths associated with insulin resistance with work by Reaven. To those who knew him, Reaven was an inspiration, and he will be remembered for his scientific rigor, productivity, and lifelong fight for truth and discovery. His work remains invaluable and relevant even today.

\section{CONFLICTS OF INTEREST}

No potential conflict of interest relevant to this article was reported.

\section{ACKNOWLEDGMENTS}

Sun H. Kim is partially supported by the Stanford Diabetes Research Center (P30DK116074) and Bose Family Foundation.

\section{ORCIID}

Sun H. Kim https://orcid.org/0000-0003-0895-7491

\section{REFERENCES}

1. Reaven GM. Banting lecture 1988. Role of insulin resistance in human disease. Diabetes 1988;37:1595-607.

2. Fuentes AV, Pineda MD, Venkata KCN. Comprehension of top 200 prescribed drugs in the US as a resource for pharmacy teaching, training and practice. Pharmacy (Basel) 2018;6: 
E43.

3. Davies MJ, D’Alessio DA, Fradkin J, Kernan WN, Mathieu C, Mingrone $\mathrm{G}$, et al. Management of hyperglycemia in type 2 diabetes, 2018. A consensus report by the American Diabetes Association (ADA) and the European Association for the Study of Diabetes (EASD). Diabetes Care 2018;41:2669701.

4. Bailey CJ. Metformin: historical overview. Diabetologia 2017;60:1566-76.

5. UK Prospective Diabetes Study (UKPDS) Group. Effect of intensive blood-glucose control with metformin on complications in overweight patients with type 2 diabetes (UKPDS 34). Lancet 1998;352:854-65.

6. Pernicova I, Korbonits M. Metformin: mode of action and clinical implications for diabetes and cancer. Nat Rev Endocrinol 2014;10:143-56.

7. Salpeter SR, Buckley NS, Kahn JA, Salpeter EE. Metaanalysis: metformin treatment in persons at risk for diabetes mellitus. Am J Med 2008;121:149-57.

8. DeFronzo RA, Tobin JD, Andres R. Glucose clamp technique: a method for quantifying insulin secretion and resistance. Am J Physiol 1979;237:E214-23.

9. Pei D, Jones CN, Bhargava R, Chen YD, Reaven GM. Evaluation of octreotide to assess insulin-mediated glucose disposal by the insulin suppression test. Diabetologia 1994;37: 843-5.

10. Natali A, Ferrannini E. Effects of metformin and thiazolidinediones on suppression of hepatic glucose production and stimulation of glucose uptake in type 2 diabetes: a systematic review. Diabetologia 2006;49:434-41.

11. Morel Y, Golay A, Perneger T, Lehmann T, Vadas L, Pasik C, et al. Metformin treatment leads to an increase in basal, but not insulin-stimulated, glucose disposal in obese patients with impaired glucose tolerance. Diabet Med 1999;16:6505.

12. Hollenbeck CB, Johnston $P$, Varasteh BB, Chen YD, Reaven GM. Effects of metformin on glucose, insulin and lipid metabolism in patients with mild hypertriglyceridaemia and non-insulin dependent diabetes by glucose tolerance test criteria. Diabete Metab 1991;17:483-9.

13. Reaven GM. Effect of metformin on various aspects of glucose, insulin and lipid metabolism in patients with non-insulin-dependent diabetes mellitus with varying degrees of hyperglycemia. Diabetes Metab Rev 1995;11:S97-108.

14. Madiraju AK, Qiu Y, Perry RJ, Rahimi Y, Zhang XM, Zhang D, et al. Metformin inhibits gluconeogenesis via a re- dox-dependent mechanism in vivo. Nat Med 2018;24:138494.

15. Abbasi F, Kamath V, Rizvi AA, Carantoni M, Chen YD, Reaven GM. Results of a placebo-controlled study of the metabolic effects of the addition of metformin to sulfonylurea-treated patients. Evidence for a central role of adipose tissue. Diabetes Care 1997;20:1863-9.

16. Abbasi F, Carantoni M, Chen YD, Reaven GM. Further evidence for a central role of adipose tissue in the antihyperglycemic effect of metformin. Diabetes Care 1998;21:1301-5.

17. Swislocki AL, Chen YD, Golay A, Chang MO, Reaven GM. Insulin suppression of plasma-free fatty acid concentration in normal individuals and patients with type 2 (non-insulindependent) diabetes. Diabetologia 1987;30:622-6.

18. Shen SW, Reaven GM, Farquhar JW. Comparison of impedance to insulin-mediated glucose uptake in normal subjects and in subjects with latent diabetes. J Clin Invest 1970;49: 2151-60.

19. Sullivan JE, Brocklehurst KJ, Marley AE, Carey F, Carling D, Beri RK. Inhibition of lipolysis and lipogenesis in isolated rat adipocytes with AICAR, a cell-permeable activator of AMP-activated protein kinase. FEBS Lett 1994;353:33-6.

20. Daval M, Diot-Dupuy F, Bazin R, Hainault I, Viollet B, Vaulont S, et al. Anti-lipolytic action of AMP-activated protein kinase in rodent adipocytes. J Biol Chem 2005;280: 25250-7.

21. Zhou G, Myers R, Li Y, Chen Y, Shen X, Fenyk-Melody J, et al. Role of AMP-activated protein kinase in mechanism of metformin action. J Clin Invest 2001;108:1167-74.

22. Zhang T, He J, Xu C, Zu L, Jiang H, Pu S, et al. Mechanisms of metformin inhibiting lipolytic response to isoproterenol in primary rat adipocytes. J Mol Endocrinol 2009; 42:57-66.

23. Abbasi F, Blasey C, Reaven GM. Cardiometabolic risk factors and obesity: does it matter whether BMI or waist circumference is the index of obesity? Am J Clin Nutr 2013;98: 637-40.

24. Piche ME, Poirier P, Lemieux I, Despres JP. Overview of epidemiology and contribution of obesity and body fat distribution to cardiovascular disease: an update. Prog Cardiovasc Dis 2018;61:103-13.

25. Alberti KG, Eckel RH, Grundy SM, Zimmet PZ, Cleeman JI, Donato KA, et al. Harmonizing the metabolic syndrome: a joint interim statement of the International Diabetes Federation Task Force on Epidemiology and Prevention; National Heart, Lung, and Blood Institute; American Heart As- 
sociation; World Heart Federation; International Atherosclerosis Society; and International Association for the Study of Obesity. Circulation 2009;120:1640-5.

26. Grundy SM, Cleeman JI, Daniels SR, Donato KA, Eckel RH, Franklin BA, et al. Diagnosis and management of the metabolic syndrome: an American Heart Association/National Heart, Lung, and Blood Institute scientific statement: executive summary. Crit Pathw Cardiol 2005;4:198-203.

27. Reaven GM. The metabolic syndrome: requiescat in pace. Clin Chem 2005;51:931-8.

28. Reaven G. All obese individuals are not created equal: insulin resistance is the major determinant of cardiovascular disease in overweight/obese individuals. Diab Vasc Dis Res 2005;2:105-12.

29. Farin HM, Abbasi F, Reaven GM. Body mass index and waist circumference correlate to the same degree with insulin-mediated glucose uptake. Metabolism 2005;54:1323-8.

30. Abbasi F, Malhotra D, Mathur A, Reaven GM, Molina CR. Body mass index and waist circumference associate to a comparable degree with insulin resistance and related metabolic abnormalities in South Asian women and men. Diab Vasc Dis Res 2012;9:296-300.

31. Sung KC, Ryu S, Reaven GM; Health Screening Group at Kangbuk Samsung Hospital. Relationship between obesity and several cardiovascular disease risk factors in apparently healthy Korean individuals: comparison of body mass index and waist circumference. Metabolism 2007;56:297-303.

32. Abbasi F, Mathur A, Reaven GM, Molina CR. Cardiometabolic risk in South Asian inhabitants of California: hypertriglyceridemic waist vs hypertriglyceridemic body mass in- dex. Ethn Dis 2016;26:191-6.

33. Tchernof A, Despres JP. Pathophysiology of human visceral obesity: an update. Physiol Rev 2013;93:359-404.

34. Fung J. The obesity code. Brunswick: Greystone Books; 2016.

35. Bhat S, Abbasi F, Blasey C, Reaven G, Kim SH. Plasma glucose and insulin responses to mixed meals: impaired fasting glucose re-visited. Diab Vasc Dis Res 2011;8:271-5.

36. Leavens KF, Birnbaum MJ. Insulin signaling to hepatic lipid metabolism in health and disease. Crit Rev Biochem Mol Biol 2011;46:200-15.

37. Zavaroni I, Zuccarelli A, Gasparini P, Massironi P, Barilli A, Reaven GM. Can weight gain in healthy, nonobese volunteers be predicted by differences in baseline plasma insulin concentration? J Clin Endocrinol Metab 1998;83:3498-500.

38. McLaughlin T, Abbasi F, Carantoni M, Schaaf P, Reaven G. Differences in insulin resistance do not predict weight loss in response to hypocaloric diets in healthy obese women. $\mathrm{J}$ Clin Endocrinol Metab 1999;84:578-81.

39. McLaughlin T, Abbasi F, Lamendola C, Kim HS, Reaven GM. Metabolic changes following sibutramine-assisted weight loss in obese individuals: role of plasma free fatty acids in the insulin resistance of obesity. Metabolism 2001;50: 819-24.

40. Gardner CD, Trepanowski JF, Del Gobbo LC, Hauser ME, Rigdon J, Ioannidis JPA, et al. Effect of low-fat vs low-carbohydrate diet on 12-month weight loss in overweight adults and the association with genotype pattern or insulin secretion: the DIETFITS randomized clinical trial. JAMA 2018; 319:667-79. 